\title{
Simposio Una Revisión Crítica del Sistema Interamericano de Derechos Humanos: Pasado, Presente y Futuro
}



$\varepsilon$ Sistema Interamericano de Derechos Humanos (SIDH) se erige en el marco de la Organización de Estados Americanos (OEA) a través de diferentes instrumentos normativos, entre los cuales se ubican preferentemente la Declaración Americana sobre Derechos y Deberes del Hombre y la Convención Americana sobre Derechos Humanos. Este Sistema reconoce un catálogo de derechos básicos con fuerza obligatoria para los Estados que lo componen, a la vez que instituye órganos que velan por su cumplimiento. La Comisión Interamericana de Derechos Humanos y la Corte Interamericana de Derechos Humanos constituyen los grandes pilares del Sistema y, en el marco de sus funciones y atribuciones, colaboran con la efectiva promoción y satisfacción de los derechos humanos en el hemisferio.

A lo largo de su historia, fueron incontables los logros del Sistema Interamericano. Sin perjuicio de ello, en la actualidad se ve interpelado por diferentes obstáculos y desafíos que deben encararse y superarse, con el objetivo último de garantizar el respeto de los derechos humanos y de crear institucionalidad democrática en países castigados por dictaduras, regímenes autoritarios, conflictos armados internos y altísimos índices de pobreza, discriminación y violencia.

Los éxitos que el Sistema ha logrado y los desafíos más críticos que actualmente enfrenta, nos han motivado a realizar el Simposio que aquí se presenta. Este encuentro académico aúna los esfuerzos de once personas comprometidas, desde diferentes perspectivas, lugares y posiciones, con la protección y realización de los derechos humanos a través de la utilización del Sistema Interamericano. Estas personas ofrecen miradas académicas, políticas y prácticas sobre puntos críticos reflejados en cinco diferentes preguntas realizadas por el Centro de Derechos Humanos. Confiamos que las opiniones de importantes hombres y mujeres que se han relacionado estrechamente con el Sistema desde las filas de la Comisión Interamericana, la Corte Interamericana, las Organizaciones No Gubernamentales, la academia y diferentes Estados, ofrezcan un cabal reflejo del estado de discusión en la materia y que, a la vez, se conviertan en un valioso aporte de cara al futuro.

\section{PARTICIPARON EN EL SIMPOSIO:}

Gustavo Gallón Giraldo, Director de la Comisión Colombiana de Juristas; Luz Marina Monzón Cifuentes, Abogada de la Comisión Colombiana de Juristas.

Juan José Gómez Camacho, Embajador de México en Singapur y, de manera concurrente, ante la Unión de Myanmar y el Sultanato de Brunei.

Claudio Grossman, Chair del Consejo Consultivo, Academia de Derechos Humanos y Derecho Internacional Humanitario, American University, Washington College of Law; Robert K. Goldman; Vice-Chair del Consejo Consultivo, Academia de Derechos Humanos y Derecho Internacional Humanitario, American University, Washington College of Law; Claudia Martin, Profesora y Directora de la Academia de Derechos Humanos y Derecho Internacional Humanitario, American University, Washington College of Law; Diego Rodríguez-Pinzón, Profesor y Director de la Academia de Derechos Humanos y Derecho Internacional Humanitario, American University, Washington College of Law.

Viviana Krsticevic, Directora Ejecutiva, Centro por la Justicia y el Derecho Internacional (CEJIL). Pedro Nikken, Ex Presidente de la Corte Interamericana de Derechos Humanos; Consejero Permanente y ex Presidente del Instituto Interamericano de Derechos Humanos.

Mónica Pinto, Doctora en Derecho y Profesora Titular Regular de Derecho Internacional Público y de Derechos Humanos y Garantías, Facultad de Derecho, Universidad de Buenos Aires.

Paulo Vannuchi, Secretario Especial de Derechos Humanos, Presidencia de la República Federativa de Brasil. 


\section{Presente y Futuro del SIDH}

¿Qué diagnóstico y evaluación generales puede hacer sobre el funcionamiento del Sistema Interamericano de Protección de Derechos Humanos? ¿Cuáles son sus principales fortalezas y debilidades? ¿Cuáles son los desafíos más importantes que enfrenta?

1. Presente y Futuro del SIDH

\section{GUSTAVO GALLÓN GIRALDO, LUZ MARINA MONZÓN CIFUENTES}

El Sistema Interamericano de Derechos Humanos se ha convertido en un instrumento de gran relevancia para la protección de los derechos humanos en el hemisferio. La presentación creciente de casos desde sus diversos países miembros así lo indica. Esta importancia regional tiene su origen en el papel fundamental que en momentos críticos ha desarrollado el Sistema en relación con situaciones de graves violaciones de derechos humanos. Por citar un ejemplo, la región pudo presenciar la actuación del SIDH frente a Perú y, sin lugar a dudas, fue su sistemático seguimiento aquello que contribuyó al restablecimiento de las garantías de las personas y de las condiciones materiales de democracia y estado de derecho en el país.

En términos generales, los casos decididos, las manifestaciones públicas y la presencia periódica en lugares donde se presentan graves violaciones a los compromisos internacionales, son formas de cumplimiento de las funciones atribuidas al SIDH que le dan credibilidad y que generan confianza en sus usuarios.

Por otro lado, el SIDH se vio fortalecido por las reformas de sus Reglamentos de mayo de 2001 en la Comisión Interamericana (CIDH) y de junio de 2001 en la Corte Interamericana (Corte IDH), las cuales fueron producto de juiciosos debates e intercambios en diversos escenarios con los usuarios. En alguna medida, dichas reformas lograron responder a las inquietudes y dificultades detectadas en relación con la estructura de procedimientos: etapas, plazos y formas de participación, entre otras. Asimismo, permitieron brindar mayor seguridad jurídica a todos los actores que intervienen en los trámites ante el SIDH. Particularmente, con relación a la Corte, facilitaron el desarrollo y sustento de una jurisprudencia que brinda seguridad jurídica a las partes respecto del alcance y contenido de los derechos y de las obligaciones internacionales de los Estados en materia de derechos humanos.

Las debilidades que presenta el Sistema consisten principalmente en la ausencia de mecanismos de seguimiento de sus propias decisiones. Así, los retos que enfrenta en esta etapa de su desarrollo se vinculan con la implementación eficaz y oportuna de mecanismos jurídicos y políticos de cumplimiento de sus decisiones; que generen las condiciones para transformar las prácticas estatales que originan violaciones de derechos humanos y denuncias. En este punto, el gran desafío es garantizar, en el marco de sus funciones, el efectivo acceso a la justicia a nivel regional. 1. Presente y Futuro del
SIDH

de México ${ }^{1}$. En esa medida, mi opinión siempre podrá mostrarse como parcial o subjetiva. No obstante, trataré de que no lo sea.

\footnotetext{
1 Entre agosto de 1997 y diciembre de 2000 me desempeñé como Representante Alterno de México ante la Organización de Estados Americanos (OEA). Asimismo, desde diciembre de 2000 a enero de 2006 fui Director General de Derechos Humanos y Democracia de la Cancillería mexicana. En ambos casos, mi función principal fue la de representar al Estado
} 
Los méritos del Sistema Interamericano son, según creo, incuestionables. Sin embargo, la pregunta es si son suficientes y aceptables. En mi opinión la respuesta es negativa. Tengo la impresión de que el Sistema se ha vuelto esclerótico y frecuentemente desfasado frente a las realidades y necesidades del hemisferio. Varias razones explican esta afirmación.

Por un lado, la Comisión Interamericana ( $\mathrm{CIDH})$ no ha logrado desprenderse de la imagen de parcialidad frente a los Estados y, curiosamente, en ocasiones también frente a las víctimas. Las tensiones que existen entre la $\mathrm{CIDH}$ y los restantes actores son desproporcionadas y muy dañinas.

A su vez, los Estados en general se niegan a dotar, sobre todo a la Comisión, de las herramientas necesarias $y$, especialmente, de la confianza requerida.

De esta forma, el debate sobre la necesaria reforma del Sistema siempre ha sido obstaculizado por una profunda desconfianza entre la $\mathrm{CIDH}$ y los Estados, por las sensaciones recíprocas de falta de transparencia, por la frecuente y extrema simplificación de los problemas que sufren los Estados, y por la descalificación automática de opiniones que no resultan políticamente correctas o admisibles. Estos son problemas bien conocidos por los diferentes actores del SIDH (órganos, Estados y ONG's usuarias, principalmente).

Finalmente, debe destacarse que el Sistema Interamericano tiene enormes ventajas. Las más importantes son su vocación y su experiencia. Por ello, precisamente, es necesario debatir sincera y constructivamente acerca de los serios retos existentes.

1. Presente y Futuro del SIDH

\section{CLAUDIO GROSSMAN, ROBERT K. GOLDMAN, CLAUDIA MARTIN Y DIEGO RODRÍGUEZ-PINZÓN}

El Sistema Interamericano de Derechos Humanos goza de una gran legitimidad y prestigio en el hemisferio debido, entre otras cosas, a las acciones de sus órganos contra la impunidad; al desarrollo de novedosas herramientas políticas (ej. visitas in loco) y jurídicas (ej. evidencia circunstancial) para confrontar violaciones de derechos humanos; al amplio espectro de reparaciones ordenadas en casos individuales, y al uso creativo y efectivo de los acuerdos amistosos. Es realmente sorprendente que la Comisión Interamericana de Derechos Humanos (en adelante "Comisión" o "CIDH") y la Corte Interamericana de Derechos Humanos (en adelante "Corte") hayan podido desplegar una acción efectiva durante estas décadas, frente a la adversidad política y de recursos que han tenido que confrontar.

Sin embargo, el Sistema Interamericano opera en el seno de la Organización de los Estados Americanos (OEA), que es un organismo políticamente polarizado y en crisis financiera permanente. Dicha organización ha renunciado constantemente a ejercer su función de garante colectivo del sistema que sus propios miembros crearon. Debido a ello, no es previsible que la Comisión o la Corte vayan a recibir el apoyo necesario para ejercer su mandato de manera adecuada. Por lo tanto, estos órganos, y en particular la Comisión, continuarán dependiendo de donaciones de algunos Estados para desarrollar las actividades más esenciales, lo cual no es saludable. Esta es posiblemente una de las mayores debilidades del Sistema.

en diferentes procedimientos ante el Sistema Interamericano de Derechos Humanos, entre los cuales cabe destacar el único litigio que México ha enfrentado en la Corte Interamericana -Caso Martín del Campo Dodd vs. Estados Unidos Mexicanos-. Asimismo, en mi calidad de Director General de Derechos Humanos y Democracia representé al Estado en la Comisión de Derechos Humanos de las Naciones Unidas (ONU).

Actualmente poseo el cargo de Embajador de México en Singapur y, de manera concurrente, ante la Unión de Myanmar y el Sultanato de Brunei. 
Al explorar las fortalezas y las debilidades es necesario separar el análisis entre la Comisión y la Corte. La Corte es el órgano jurisdiccional, mientras que la Comisión tiene un mandato diverso que la ocupa tanto en casos individuales como en asuntos político-diplomáticos. La Corte sustenta su prestigio e integridad en la calidad de sus decisiones judiciales. Esta se fortalecerá o se debilitará dependiendo de la legitimidad de dichas sentencias.

La Comisión tiene como una de sus mayores fortalezas el apoyo de la sociedad civil del hemisferio que, aunque incipiente, ha sido lo suficientemente eficaz para protegerla de los repetidos ataques de ciertos gobiernos. Este apoyo es el resultado del trabajo desarrollado durante décadas, en el cual la Comisión ha privilegiado a la víctima como el corazón de su accionar. A ello se ha sumado la expansión de la labor de las organizaciones no gubernamentales de derechos humanos del ámbito puramente local al espacio internacional. También ha contribuido el trabajo creativo de la Comisión que, frente a situaciones como las de Argentina durante y después de la dictadura, Perú en el gobierno de Fujimori, o Colombia, ha desplegado eficazmente todas su potestades políticas (comunicados de prensa, visitas in loco, informes generales y especiales) y jurídicas (adjudicación de casos y presentación de demandas ante la Corte).

Aparte de las mencionadas limitaciones en el capital político y económico de la OEA, los mayores desafíos del Sistema radican en satisfacer en forma adecuada las expectativas que ha creado. Paradójicamente, la Comisión y la Corte pueden llegar a ser víctimas de su propio éxito si no logran responder adecuadamente a los requerimientos de sus usuarios. Asimismo, es importante diseñar una estrategia coherente frente a nuevos temas emergentes, tales como los derechos económicos, sociales y culturales en una región donde las desigualdades son más agudas que en el resto del mundo.

Finalmente, es importante que aquellos países como Estados Unidos, Canadá y otros anglófonos del Caribe se integren de Ileno al Sistema Interamericano de Derechos Humanos. La ratificación de los tratados más importantes, así como la aceptación de la jurisdicción contenciosa de la Corte, son pasos cruciales para hablar de un Sistema propiamente "interamericano". Este salto a la mayoría de edad lo consolidaría como uno de los más avanzados y diversos del planeta, contando con la riqueza de la gran variedad de visiones políticas, jurídicas, sociales y culturales que caracterizan al continente. De lo contrario, seguiremos viendo los problemas y distorsiones que periódicamente genera esta asimetría jurídica y política, y se continuará privando a todos los habitantes de las Américas del derecho a beneficiarse de los mecanismos del Sistema.

\section{Presente y Futuro del} SIDH

humanos de América. Aun contando con escasos recursos y limitada capacidad de coacción, el SIDH ha permitido salvar vidas; dar voz a miles de víctimas de violaciones de derechos humanos; indemnizar a sobrevivientes y familiares; legitimar y respaldar reclamos de gran peso moral en situaciones de opresión; impulsar procesos de incorporación de valores democráticos en el discurso público en Latinoamérica; lograr la modificación de leyes y de sentencias judiciales; brindar elementos para la elaboración de legislación y políticas públicas, etcétera.

Sin embargo, aquél no ha podido dar respuesta a la mayoría de las víctimas que buscan justicia, ni ha intervenido en forma consistente en muchas situaciones críticas de derechos humanos en el hemisferio. Tampoco ha actuado con el mismo rigor frente a todas ellas ni ha promovido el desarrollo de su labor en diversos temas y regiones. 
Ahora bien, el futuro del SIDH está ligado en buena medida a los desafíos que impone el contexto regional. Las democracias de América enfrentan situaciones estructurales de tolerancia a los abusos y a las graves violaciones de los derechos fundamentales de la ciudadanía. Entre otras razones, por la exclusión social de enormes sectores de la población, cuya situación de pobreza limita su acceso real a la arena política, a la administración de justicia para la prevención y resolución de sus conflictos, a una educación y salud adecuadas, y a la protección contra la discriminación y la violencia.

\section{Presente y Futuro del} SIDH

\section{PEDRO NIKKEN}

Orientación general. El SIDH ha tenido una línea de actuación que, en general, se corresponde con su función tutelar de los derechos humanos.

Su tendencia persistente ha sido la interpretación del derecho en el sentido más favorable a la presunta víctima, en conformidad con las normas internacionales. La composición de los órganos del SIDH por personas independientes no vinculadas formalmente con gobiernos, es la que menos se presta a su politización. Sin embargo, los avatares del regateo diplomático han acarreado la elección ocasional de personas sin la trayectoria y el compromiso adecuados. Esto puede vulnerar la independencia e idoneidad del Sistema.

La principal fortaleza del SIDH es la credibilidad de sus actuaciones que nunca ha podido ser rebatida sustantivamente. En ese contexto, un Iogro significativo es el de representar un referente generalmente aceptado sobre los derechos humanos y las obligaciones estatales respecto de ellos. Su debilidad más notoria radica en que el apoyo de los Estados es, en general, meramente nominal: (a) el SIDH carece de recursos humanos y materiales para enfrentar la demanda que recibe; (b) los Estados, como partes en un tratado, están llamados a ser los garantes últimos de su cumplimiento, pero la inejecución de las decisiones de los órganos del SIDH no es atendida por los órganos políticos de la OEA (Consejo Permanente -CP- y Asamblea General -AG-), donde se detecta una suerte de recíproca tolerancia en la resistencia pasiva a cumplir ciertas decisiones de la Comisión y la Corte Interamericanas. Otra debilidad es su limitada acción en el campo de Ios DESC, gravemente vulnerados en las Américas.

Una fuente de preocupación importante es la tendencia al cumplimiento selectivo de las sentencias de la Corte, en especial cuando dicho incumplimiento está precedido de una admisión de responsabilidad por parte del Estado. Es frecuente que la parte de la sentencia que está referida a la indemnización del daño (material o inmaterial) sea cumplida, aunque con demoras y regateos. Por el contrario, las medidas de restitución, no repetición y satisfacción tienden a ser desatendidas. Esto refleja cierta propensión a reducir a las violaciones de derechos humanos a una suerte de tarifa: si el Estado admite su responsabilidad, la condena pierde vigor como sanción; pero si además la reparación se limita en la práctica al pago de sumas de dinero, la responsabilidad nunca es una restitutio in integrum y se burla así el sentido regenerador implícito en la protección internacional de los derechos humanos.

Finalmente, no se ha explorado suficientemente el reconocimiento de efectos erga omnes de decisiones "de principio" adoptadas en el contexto de casos individuales (ver respuesta a pregunta $\mathrm{N}^{\mathrm{o}} 2$ ). 1. Presente y Futuro del
SIDH

mente a la urgencia. En ese hacer, ha participado de las características del Sistema Interamericano

El Sistema Interamericano de Derechos Humanos es un sistema regional que se ha gestado y ha crecido de modo heterodoxo, respondiendo normativa-

\section{MÓNICA PINTO}


general. Sin embargo, a diferencia de otros capítulos, el de los derechos humanos ha demostrado aptitudes de efectividad.

En los 70, sin tratado de base, la Comisión Interamericana (CIDH) tramitó peticiones, condujo visitas in loco y produjo informes que motivaron los primeros pronunciamientos de los órganos políticos de la comunidad institucionalizada, condenando las prácticas de la desaparición forzada de personas, de la ejecución sumaria y de la tortura sistemática.

En los 80, los gobiernos elegidos por las democracias reinstaladas se transformaron en los nuevos interlocutores del Sistema. Se inició un reacomodamiento en las relaciones que, tenuemente, se extendieron a la Corte Interamericana (Corte IDH).

En los 90, Comisión y Corte buscaron un acercamiento. La incentivación de la competencia contenciosa del tribunal y las solicitudes de medidas provisionales testimoniaron una cooperación a fomentar.

El siglo XXI abre a una América desolada por la pobreza, la exclusión y la discriminación. Hay una ciudadanía social a la que no todos los gobiernos dan tratamiento adecuado.

La praxis de la Comisión ha acompañado las urgencias que se presentaron en el hemisferio, contribuyendo decididamente a la consolidación del estado de derecho y del respeto a los derechos humanos, desde una perspectiva político-jurídica. La Corte, por su parte, es el ejemplo de un tribunal que a caballo de los tiempos hace derecho, aunque el volumen de los casos que debe resolver, a la luz de los recursos disponibles, se proyecte como un importante obstáculo para mantener estándares de rigor jurídico.

Así, el SIDH ha prestado un increíble servicio a los ciudadanos y ciudadanas de las Américas. Su capacidad de adaptación a los cambios contextuales ha sido admirable. Debe seguir creciendo y asegurando un escrutinio estricto de la observancia de los derechos humanos por los gobiernos americanos. Para ello debe proponerse una efectividad en todos sus ámbitos, fomentando la adopción de medidas que salven la distancia entre el dispositivo internacional y la solución concreta de los casos que se analizan.

La tarea de controlar la observancia de los derechos humanos, a su vez, exige de esfuerzos de los gobiernos: la elección de las personas mejor preparadas para el desempeño de los cargos, la asignación de los recursos económicos necesarios para que el Sistema funcione adecuadamente, la decisión política de crear mecanismos que garanticen la implementación material de las decisiones, entre otros. Los órganos del SIDH se verán así más acompañados y extremarán sus esfuerzos para que éste sea creíble, efectivo, riguroso, menos expuesto y más eficaz.

1. Presente y Futuro del SIDH al Sistema Universal iniciado después de la Declaración de 1948. Puede decirse que la reconstrucción de los derechos humanos -tanto a escala mundial como continental- ha representado un nuevo despertar y una reacción al horror de la Segunda Guerra, con su gigantesca destrucción de vidas humanas y con el Holocausto.

* Esta participación fue traducida del portugués por María Soledad Feliu. 
En ese sentido, asumiendo un carácter progresista e innovador, el SIDH forma parte de los sistemas regionales de protección, contribuyendo a la difusión regional de que ya no es el Estado el único sujeto de derecho internacional sino que también se comienza a aceptar la lucha de las personas por sus derechos en el ámbito mundial. Este movimiento da inicio a la revisión del concepto tradicional de soberanía del Estado, admitiéndose un cierto grado de intervención internacional en el contexto interno, en nombre de la garantía y del respeto por los derechos humanos.

Continuando con el análisis histórico de la evolución del derecho internacional de los derechos humanos, nos encontramos con Norberto Bobbio, que en su libro El tiempo de los derechos explica la idea de que "los derechos humanos nacen como derechos naturales universales, se desarrollan como derechos positivos particulares (cuando cada Constitución incorpora Declaraciones de Derecho), para finalmente encontrar su plena realización como derechos positivos universales" ${ }^{2}$.

Analizando el escenario histórico de Brasil, se observa que solamente después de la democratización del país, con la publicación de la Constitución de 1988, conocida también como "Constitución Ciudadana", se concretó el proceso evolutivo de garantías a los derechos fundamentales de sus ciudadanos y ciudadanas. A pesar de que Brasil fue uno de los últimos Estados en adherir a la Convención Americana sobre Derechos Humanos (1992), se puede afirmar actualmente que el país ha avanzado rápidamente en la incorporación de los derechos que ésta ampara a su ordenamiento jurídico interno.

El SIDH, con su efectivo mecanismo de monitoreo, compuesto por la Comisión Interamericana de Derechos Humanos y por la Corte Interamericana de Derechos Humanos, ejerce un rol fundamental en la consolidación de la democracia en el continente americano, garantizando una vía subsidiaria y suplementaria a las vías internas, en los casos de violaciones que no hayan recibido respuestas satisfactorias.

Los Estados parte de la Convención Americana, al asumir la obligación de respetar sus disposiciones, se comprometen a no violar los derechos allí amparados, pero también a asegurar el libre y pleno ejercicio de dichos derechos a toda la ciudadanía. Partiendo de este supuesto, es deber de cada Estado parte promover el Sistema Interamericano y hacerlo accesible a aquellas personas que sientan sus derechos violados al no encontrar atención a sus clamores en su sistema interno de protección.

Sin embargo, al mismo tiempo en que se desea una mayor publicidad y un amplio acceso al $\mathrm{SIDH}$, en nombre de su universalidad, se teme que el constante aumento del número de casos pueda ser un obstáculo para la promoción de la justicia, reproduciéndose en el ámbito regional las innumerables dificultades encontradas en el contexto interno de los países, entre ellas, la demora excesiva de los procesos judiciales. Tal vez éste sea el mayor reto que el Sistema Interamericano debe enfrentar.

2 N. Bobbio, El tiempo de los derechos, Madrid, España, Ed. Sistema, p. 68. 


\section{Función del SIDH}

¿Es posible pensar en el SIDH como un último bastión de justicia frente a todas las violaciones de $\mathrm{DDHH}$ que no encuentren remedio en los niveles nacionales? $i \mathrm{O}$, en cambio, el SIDH debe seleccionar estratégicamente sus casos y concentrarse en la determinación de estándares en materia de DDHH y de obligaciones estatales? Si lo primero, ¿cómo abordar las probables expectativas crecientes de los usuarios del Sistema y el aumento continuo del número de casos? ¿Son las opciones propuestas incompatibles entre sí o pueden coexistir en forma eficiente? Si lo último, ¿bajo qué criterios debería efectuarse dicha selección?

2. Función del SIDH

\section{GUSTAVO GALLÓN GIRALDO, LUZ MARINA MONZÓN CIFUENTES}

En este momento el SIDH es percibido como el último bastión de justicia ante la ausencia de respuesta y protección de los Estados en el ámbito interno. Esa percepción ha incrementado de manera paulatina el número de casos que tramitan ante él. Este camino, tal como lo han evaluado algunos Comisionados y Jueces, puede conducir a su desborde $y$, por ende, a su ineficacia.

El SIDH, como cualquier otro sistema de protección internacional de derechos humanos, tiene una naturaleza que no puede perderse de vista, especialmente en su práctica. Esa naturaleza se vincula con el hecho de constituir un mecanismo subsidiario y coadyuvante a los sistemas domésticos de protección. En consecuencia, si bien el SIDH tiene la función de proteger los derechos humanos mediante la resolución de casos, también posee la de contribuir a que los Estados respeten esos derechos y garantías. Es decir, es posible constituirse en último bastión de justicia ante la desprotección estatal y, a la vez, tomar estratégicamente casos que tengan la potencialidad de incidir de manera general en el cambio de situaciones o prácticas estatales que provocan recurrentes violaciones de derechos humanos en países o regiones determinadas.

Así, los criterios para compatibilizar estas dos funciones del Sistema deben construirse a partir del estudio y seguimiento cuidadoso de las decisiones adoptadas en los diversos casos; en los informes producidos con ocasión de las visitas in loco; en informes sobre situaciones particulares de derechos determinados; o en informes de las relatorías, entre otros. En efecto, cuando la Comisión toma decisiones en diversos casos que involucran al mismo país en un período determinado puede, más allá de las particularidades propias de cada caso, identificar algunas situaciones recurrentes de actuación oficial o la existencia de contextos materiales propicios para generar violaciones. Asimismo, también puede identificar patrones y violaciones de derechos humanos más o menos homogéneas. En el futuro, este tipo de valoración debe determinar las estrategias y criterios de actuación de cara a cada Estado, para identificar casos a tramitar, para asumir una agenda de trabajo frente a ellos y para incidir en los cambios sustantivos que demandan las causas de las violaciones. En general, existen aspectos que son comunes a la región, tales como la impunidad, la ausencia de políticas públicas serias y sólidas que prevengan violaciones de derechos humanos y el debilitamiento del Estado de Derecho y la democracia en el hemisferio. Hacia estos aspectos deberían dirigirse primordialmente las selecciones estratégicas, que a su vez deberían ser estructuradas y conversadas con los usuarios del Sistema, que cada vez están mejor organizados.

\section{JUAN JOSÉ GÓMEZ CAMACHO}

2. Función del SIDH

En ningún escenario es posible pretender que el SIDH sea el último bastión de justicia; por más deseable que pueda parecer. Simplemente, no existen 
ni existirán las condiciones para ello. La discusión sobre esta posibilidad es, en el mejor de los casos, innecesaria.

La segunda posibilidad planteada por la pregunta es evidentemente la vía más realista, pero no excluye otras alternativas como la cooperación y la asistencia.

La selección de asuntos es un mecanismo natural y eficiente, y en buena medida la Comisión lo utiliza. Esta alternativa, con la que estoy enteramente de acuerdo, enfrenta retos enormes. El más importante es el de las percepciones. Muy desafortunadamente, mientras los órganos y los Estados no superen los problemas de desconfianza mutua, esta alternativa de selección de casos, no obstante ser la mejor y la única factible en materia jurisdiccional, será causa y motivo de mayores tensiones.

Por otro lado, me gustaría retomar nuevamente el tema de la cooperación, asunto sobre el cual he insistido abiertamente durante los últimos años. En términos generales, la principal dificultad para la protección de derechos humanos en el hemisferio responde a problemas estructurales y profundos existentes en todos los países. Mientras estos problemas no se superen, con o sin Sistema Interamericano, las violaciones seguirán incrementándose.

Los Estados tienen que equipar a la Comisión para estas tareas y reconocerle legitimidad y capacidad para llevarlas adelante. Todos los actores tienen que abandonar la constante apelación a la llamada "voluntad política" (o falta de ella) para explicar y justificar las evidentes fallas. Estas argumentaciones son socorridas, simplistas, y no permiten construir un nuevo entendimiento entre los Estados y el SIDH.

\section{Función del SIDH}

\section{CLAUDIO GROSSMAN, ROBERT K. GOLDMAN, CLAUDIA MARTIN Y DIEGO RODRÍGUEZ-PINZÓN}

La falta de recursos que ha afectado al Sistema Interamericano históricamente y el número creciente de peticiones que recibe, sumado a la experiencia comparada de otros sistemas internacionales de derechos humanos, parecen sugerir que no es posible concebirlo como una última instancia para resolver todas las violaciones de derechos humanos en las Américas. Esta situación, sin embargo, no conlleva necesariamente a afirmar que la selección estratégica de casos sea la única alternativa disponible para resolver el dilema de la acumulación de peticiones. También, en el contexto de la reforma del Sistema, se han discutido otros mecanismos para agilizar el trámite de peticiones que podrían explorarse como opciones para mejorar la eficiencia de sus órganos y, al mismo tiempo, resolver las denuncias que se presentan a su consideración. En primer lugar, una alternativa que se encuentra contemplada reglamentariamente es la consolidación de peticiones que reflejen hechos o patrones de violaciones similares que podrían ser resueltos a través de una única decisión. A ello podría sumarse el desarrollo de un método de decisiones per curiam, en el cual los órganos del Sistema resolvieran mediante un informe o sentencia breve casos que reflejen cuestiones legales ya definidas con claridad en la jurisprudencia existente. Por otro lado, la Comisión podría considerar emitir un informe final en un caso (artículo 51) y no referirlo a la Corte cuando éste plantee cuestiones fácticas y jurídicas ya resueltas por el tribunal en una sentencia previa. En dicha situación, la Comisión podría establecer reparaciones similares a las fijadas por la Corte en el caso anterior y luego supervisar su cumplimiento a través de audiencias de seguimiento. Esto sería particularmente efectivo con relación a Estados que poseen legislación interna para la implementación de decisiones y sentencias de órganos internacionales. Sin embargo, si bien estas opciones resultan instrumentales para acelerar la resolución de casos pendientes, podrían ser objeto de críticas por los usuarios del Sistema por cuanto no garantizan la decisión individualizada de cada petición, ni la revisión por parte de la Corte de casi la totalidad de las denuncias en las cuales la Comisión emite informes. 
La selección estratégica de casos como fórmula para descongestionar el Sistema de peticiones individuales también podría considerarse una alternativa viable en la medida que pudieran determinarse criterios precisos, garantizando la transparencia del proceso. La práctica actual refleja que, en cierta medida, parecería existir de facto un mecanismo de selección de casos en la forma en que la Comisión decide el orden en el que considerará las denuncias que recibe. Por ello, seleccionar de acuerdo a criterios precisos aparentemente no constituiría una regresión en la protección que ofrece actualmente el Sistema -como podrían argumentar algunos usuarios- sino más bien una contribución a la transparencia del trámite de peticiones individuales. La necesidad de fijar estándares claros parecería descartar en principio un procedimiento de certiorari, puesto que éste opera sobre la base de la discreción del tribunal para escoger los asuntos sobre los que se pronunciará. En el marco del Sistema Interamericano, en el cual la composición de los miembros de sus órganos y de su personal es fundamental para garantizar un funcionamiento apropiado, autorizar una selección discrecional de los casos a resolver podría dar lugar a decisiones arbitrarias que excluirían la consideración de asuntos controversiales o novedosos.

La determinación de criterios de selección requeriría de un debate que va mas allá del alcance de este documento, dada la complejidad del tema. Sin embargo, a los efectos de elaborar dichos criterios, podría considerarse la aplicación de un tratamiento diferenciado a Estados con graves violaciones de derechos humanos o a casos que planteen violaciones de derechos fundamentales como la vida o la integridad personal. Complementariamente, se podría construir un criterio de selección que permitiera a los órganos del Sistema contar con cierta discreción para evaluar el resto de los casos. De todos modos, cualquiera sea el criterio que se aplique, toda decisión de excluir la consideración de un caso debería realizarse en forma pública y razonada, exponiendo los motivos del rechazo. Aún así, un mecanismo como el planteado podría objetarse fundadamente por los usuarios del Sistema por cuanto, además de no permitir la resolución de todos los casos, también podría requerir recursos y tiempo para elaborar estas decisiones de "admisibilidad".

\section{VIVIANA KRSTICEVIC}

2. Función del SIDH

La pregunta del Anuario sobre la función del Sistema Interamericano exige abordar la pregunta recurrente e irresuelta sobre cuáles son las estrategias de protección que exige la situación actual de derechos humanos en el hemisferio, entre otras cuestiones a resolver: ¿Qué estrategias puede desarrollar el SIDH usando sus ventajas comparativas frente a otros actores de promoción y tutela de derechos a nivel interno e internacional? ¿Debe tutelar derechos o privilegiar el fortalecimiento de aquellos sistemas y actores que garantizan esos derechos? ¿Debe contribuir a mejorar las instituciones de control con estándares de protección, denuncia de situación, propuestas para el desarrollo de políticas públicas? ¿Cuáles son las alianzas que pueden consolidarse o promoverse para el desarrollo de sus objetivos y estrategias? ¿Qué herramientas son útiles para impulsar el cambio de situaciones críticas?

Claramente, la tutela directa a víctimas de violaciones de derechos humanos a través del sistema de casos ante la Comisión $(\mathrm{CIDH})$ y la Corte Interamericanas tiene que continuar siendo central en el Sistema. Me refiero concretamente a la habilidad para dar respuestas no sólo individuales a los reclamos de las víctimas, sino también colectivas, que promuevan cambios culturales, estructurales, institucionales, etcétera. De esta forma, mediante decisiones colectivas vinculantes, es posible beneficiar a conjuntos de personas más allá de aquellas que litigan casos individuales, así como fortalecer el estado de derecho y las garantías de tutela, prevenir la recurrencia de las violaciones identificadas, y evitar que haya que resolver cientos de peticiones en el mismo sentido dentro del SIDH. 
En esta línea, todavía es posible mejorar algunos aspectos procesales y sustantivos para responder a realidades que afectan a importantes sectores de la población. A modo de ejemplo, es deseable perfeccionar las medidas de acceso y litigio que permitan ofrecer soluciones vinculantes que tutelen los derechos de colectivos o grupos, capitalizando las experiencias locales existentes en la materia. Asimismo, a la hora de intervenir, uno de los desafíos de la CIDH consiste en identificar vías para articular en mayor medida el trabajo de casos con otras herramientas de promoción y tutela de derechos del SIDH, como los informes temáticos o de países.

Las prioridades de la Comisión deberían responder a los desafíos del amparo de los derechos humanos en democracia. Es decir, la protección y la promoción de la dignidad, la autonomía, la libertad y la igualdad como valores centrales. Así debería incluir una carta de navegación que comprenda las situaciones más aberrantes de opresión y miseria, como las ejecuciones, la tortura, las desapariciones, el trabajo esclavo o forzado, la violencia doméstica, el tratamiento inhumano en los centros de detención. También debe abordar las violaciones de derechos que explican y perpetúan la desigualdad, como la discriminación, la falta de garantía del acceso a la educación, las limitaciones a la participación política, la violencia rural, los factores que distorsionan la justicia, etcétera. Pese a la ampliación sustancial de la agenda del Sistema en la última década, la $\mathrm{CIDH}$ necesariamente debe incluir en ella a las situaciones vinculadas con el quiebre del principio de autonomía, como las violaciones a la libertad de expresión, al derecho de asociación, a la cultura y a la privacidad; a los derechos y libertades sindicales; a la discriminación en razón de género, raza y etnia; al derecho a la educación tutelado en el Protocolo de San Salvador; a las obligaciones positivas en materia de salud; etcétera. En ese mismo sentido, debe considerar aquellas situaciones que ponen en riesgo la libertad, como las detenciones arbitrarias, el abuso de la prisión preventiva, la privación de la tierra de los pueblos indígenas, el desplazamiento forzado y el refugio, entre otras.

Sin embargo, la agenda de casos no siempre permite responder oportunamente o con la suficiente amplitud a todas las situaciones que ameritan una respuesta del Sistema. Por ello, es clave explorar alternativas para enfrentar los desafíos señalados. La CIDH debe articular sus prioridades temáticas por país y regionales, y ampliar la agenda del SIDH para adecuar el accionar de los órganos interamericanos a las necesidades de protección en la región. Más aún, el SIDH debe fortalecer su capacidad de accionar mediante la consolidación, profundización o inicio de estrategias de interlocución con actores fundamentales. Uno de ellos, muchas veces postergado en los debates, lo constituyen las víctimas y sobrevivientes de violaciones de derechos humanos, que encuentran numerosos obstáculos para el más amplio y efectivo acceso el Sistema ${ }^{3}$. A su vez, el creciente papel de las Organizaciones No Gubernamentales de Derechos Humanos ha democratizado en mayor medida el acceso a la justicia internacional y ha garantizado nuevos canales de información y comunicación sobre temas claves que no necesariamente son relevados por la prensa local e internacional.

También el SIDH debe considerar, de modo selectivo, participar en otros espacios de construcción y debate de políticas públicas relacionadas con la temática de derechos humanos; pero el espíritu de este acercamiento no debería estar fundado en la oferta de asesorías y en la capacitación de ONG's y funcionarios/as, sino en la cooperación puntual frente a los objetivos de la agenda delimitada anteriormente.

Adicionalmente, la CIDH y la Corte deben fomentar un mayor acercamiento con los órganos políticos de la Organización de Estados Americanos (OEA); con los grupos de trabajo que debaten

3 Una de las medidas que CEJIL ha promovido para garantizar la participación de las víctimas en el Sistema es la creación de un fondo de asistencia legal. 
instrumentos convencionales; con las diversas dependencias de la Secretaría General con competencia en cuestiones vitales para la democracia y los derechos humanos; con otros cuerpos de protección como el Alto Comisionado de las Naciones Unidas para los Derechos Humanos o las relatorías de Naciones Unidas, y con organismos diseñadores, ejecutores y financistas de políticas públicas y de administración de justicia, tales como los bancos de desarrollo.

Por último, el trabajo con otras instituciones locales, como los Ombudsman y los operadores de justicia, se muestra como una línea de acción que debe ser estudiada en mayor medida.

2. Función del SIDH

\section{PEDRO NIKKEN}

¿Último bastión? El SIDH, como todo sistema internacional de protección de derechos humanos, es el último recurso potencialmente efectivo de los casos que acceden a él, pero no puede ser, materialmente, el último foro para cada uno de los casos de violaciones de los derechos humanos que no encuentran remedio en la jurisdicción nacional. No es posible universalizar el acceso al "último bastión", pero, en cambio, sí cabe generalizar los efectos de las decisiones singulares de los órganos del Sistema.

El SIDH está Ilamado a ser un mecanismo para la definición de estándares sobre el alcance y la garantía de los derechos humanos destinados a ser recogidos y aplicados en el Derecho interno. La adecuada inserción en el sistema jurídico interno (incluidas la práctica judicial y administrativa) de los estándares internacionales es el mejor conducto para asegurar la normalidad del respeto y la garantía, dentro de las jurisdicciones nacionales, de los derechos humanos internacionalmente proclamados. En un sentido inmediato, incumbe al Estado parte en un caso ante el SIDH, aplicar el artículo 2 de la Convención y adoptar las disposiciones legislativas y de otro carácter para poner en práctica en el ámbito interno las decisiones de la Comisión y la Corte. Más allá de eso, en un sentido mediato, todos los Estados partes del SIDH, o al menos de la Convención Americana, deberían disponer de mecanismos para recoger o aplicar en su sistema jurídico los estándares de aplicación general o "de principio" que surjan de cada caso individual. Por ejemplo, la Corte Suprema de Justicia de Argentina (caso Simón; sentencia de 14 de junio de 2005), aplicó criterios definidos por la Corte Interamericana en un caso atinente a Perú (caso Barrios Altos), entendiendo que la aplicación erga omnes de esos criterios obedece a "que las decisiones del Tribunal internacional mencionado han de ser interpretadas de buena fe como pautas jurisprudenciales".

Dentro de esa orientación, no caben los dilemas propios de la selección estratégica de casos. El cumplimiento de buena fe del artículo 2 de la Convención (que la Corte Interamericana ha identificado con un principio jurídico internacional evidente o allant de soi) debería conducir a la adaptación de los sistemas jurídicos nacionales a los estándares definidos por el SIDH al interpretar y aplicar el Derecho Internacional. De proceder así, se suprimirían espontáneamente normativas y prácticas perversas, a la vez que se generalizaría el efecto regenerador del sistema internacional.

Estos enfoques no satisfacen la expectativa de la creciente demanda del SIDH, ni existen otros que lo hagan. Lo que puede definir la utilidad del SIDH será, más que el volumen de víctimas amparadas, el vigor y la amplitud de la recepción interna de los criterios internacionales.

\section{MÓNICA PINTO}

2. Función del SIDH

El desarrollo de un sistema se ve sometido a incidencias de distinto tipo, incluidas las contextuales. EI SIDH dice relación evidente con el medio

en que se generó. 
La histórica y constante alternancia entre gobiernos de iure y de facto supo dar origen a la Comisión Interamericana como el único órgano a cargo de la tarea de fomentar la conciencia de los derechos humanos en los pueblos de América. Años más tarde, se la dotó de competencias para tramitar peticiones de personas y grupos que alegaran violaciones a los derechos humanos por parte de cualquier miembro de la Organización de Estados Americanos (OEA).

De allí que no resulte difícil asumir al SIDH como un último bastión de justicia frente a todas las violaciones de derechos humanos que no encuentran remedio en los niveles nacionales. Incluso, estimo que la década del liberalismo económico a ultranza en las Américas instituyó al SIDH como el único mostrador disponible para reparar los injustos cometidos a nivel nacional, aunque no siempre constituyeran violaciones a los derechos humanos stricto senso. En este sentido pueden leerse diferentes decisiones de la Comisión, por ejemplo aquellas que se vinculan con la reformulación de la doctrina de la cuarta instancia o con determinadas inadmisibilidades declaradas frente a casos originados en dicho período.

A mayor difusión del Sistema y menor dificultad para operar con él, cualquier persona encuentra incentivos para recurrir a la instancia regional, medie o no la satisfacción de los requisitos de admisibilidad. Se emprende así la búsqueda de un resultado que repare la posible violación de derechos humanos en el ámbito nacional. A la inversa, cuando el Sistema sólo es conocido por unos pocos y no es fácilmente operable por cualquiera, si la situación no alcanza niveles de política sistemática de violación de los derechos humanos sólo quienes poseen el know-how acceden.

Cabe entonces una estrategia para compatibilizar estas tensiones: la elección minuciosa de casos susceptibles de motivar un pronunciamiento del SIDH capaz de producir un impacto en el ámbito interno. Es decir, asuntos cuya solución pueda mejorar los niveles de protección y alcanzar a un universo importante de personas, por ejemplo aquellos que conducen a modificaciones legislativas aplicables en forma inmediata o en plazos breves ${ }^{4}$.

Es claro que en la experiencia del SIDH se dan simultáneamente los enfoques planteados por la pregunta. Entre otros casos, la práctica de Argentina y Chile lo atestigua. No puede pensarse que el Sistema deba acotarse al sólo pensamiento estratégico conducente al standard setting nacional, ya que en ruta quedarán varios defraudados. Empero, tampoco puede abrirse una interpretación de los derechos humanos que, sólo para satisfacer al gran público, se transforme en omnicomprensiva y residual. El Sistema debe prestar servicios, pero en la medida en que no se arriesgue a una devaluación de su importancia.

\section{PAULO VANNUCHI}

2. Función del SIDH

La aplicación de los mecanismos establecidos en el SIDH no debe desviar la responsabilidad primaria de los Estados en la protección de los derechos humanos. Esta instancia internacional deberá entrar en acción de manera suplementaria, adicional y subsidiaria, cuando se presuma el agotamiento de los recursos internos. El consentimiento voluntario del Estado en el control y en la fiscalización internacional en los casos de violaciones de derechos fundamentales debe estar vinculado necesariamente con las fallas u omisiones en las respuestas de los organismos nacionales a las violaciones mencionadas.

De este modo, el SIDH no debe interpretarse como una instancia revisora de sentencias internas, cuando éstas han sido dictadas en conformidad con los parámetros y las obligaciones interna-

4 Véase el Informe №22/94, caso 11.012, Argentina, Solución Amistosa, 20 de septiembre de 1994, en Informe Anual de la Comisión Interamericana de Derechos Humanos OEA/Ser.L/V/I/II.88 doc.9 rev. 
cionales asumidas por los Estados. En ese sentido, afirma Cançado Trindade: "Los Tribunales internacionales de derechos humanos existentes -las Cortes Europea e Interamericana de Derechos Humanos- no "sustituyen" a los Tribunales internos, y tampoco operan como tribunales de recursos o de casación de fallos de los Tribunales internos. No obstante, los actos internos de los Estados pueden venir a ser objeto de examen por parte de los organismos de supervisión internacionales, cuando se trata de verificar su conformidad con las obligaciones internacionales de los Estados en materia de derechos humanos".

Es papel de los Estados promover el SIDH y contribuir a que su acceso se le facilite a cualquier persona o entidad que juzgue haber sido víctima de violaciones. No obstante, cabe resaltar que los requisitos de admisibilidad deben respetarse en nombre de la seguridad jurídica y de la valoración de la instancia regional. La admisión indiscriminada de casos pone en riesgo la credibilidad y la funcionalidad del Sistema, amenazando su eficacia y eficiencia en la promoción y protección de los derechos humanos en todas las partes del continente americano.

Es importante destacar que al hemisferio no le interesa un sistema sobrecargado, inadecuadamente financiado y cuestionado con relación al equilibrio y la eficacia de sus sentencias. En ese sentido, cabe reflexionar sobre los criterios de selección de los casos y el impacto real que las sentencias relacionadas con éstos tendrán en el contexto regional. Deberán discutirse las decisiones que contemplen exclusivamente derechos individuales y no colectivos, y que no promuevan cambios significativos en el orden interno de un país.

\section{Procedimiento}

Nos interesaría conocer su opinión acerca de los siguientes aspectos procesales del funcionamiento actual del SIDH: (1) duración de los procedimientos ante la Comisión y la Corte, (2) producción de prueba y duplicación de funciones entre la Comisión y la Corte, (3) rol de la Comisión y de la(s) víctima(s) en los procesos contenciosos ante la Corte Interamericana.

\section{GUSTAVO GALLÓN GIRALDO, LUZ MARINA MONZÓN CIFUENTES}

3. Procedimiento

(1). En relación con los procedimientos ante la Comisión y la Corte existe una diferencia sustantiva entre los dos órganos. La Comisión registra grandes demoras en la decisión de los casos, lo cual se ha visto agravado por la posibilidad de llevarlos a la propia Corte. Es decir, en la práctica, la Comisión no resuelve casos ante la expectativa de que los peticionarios soliciten luego su presentación ante la Corte, hecho que provocaría un incremento de trabajo y una simultaneidad de demandas difícil de procesar. De alguna manera, aunque insuficiente, esta situación se ha intentado enfrentar con la creación del equipo de Corte en la Secretaría Ejecutiva.

Así, lo que se percibe es una especie de distancia entre lo que previene el Reglamento de la Comisión en cuanto al trámite y lo que sucede en la realidad. En efecto, de cara al Reglamento, una vez concluida la etapa de fondo, el caso debería ser resuelto e inmediatamente comunicado a las partes para escuchar las opiniones sobre el sometimiento a la Corte. En la práctica, lo que sucede es que el caso termina su etapa de fondo y no se produce la decisión, sin que se conozcan las razones por las cuales se produce esta fase de suspensión del trámite. Esta situación puede permanecer algunos meses, e incluso años, sin ningún tipo de actuación. En ocasiones, frente a la demora de una etapa del procedimiento, por ejemplo la admisibilidad, los peticionarios han solicitado sin éxito audiencias para impulsar casos. A su vez, tampoco la Secretaría Ejecutiva o la propia Comisión han dado el impulso adecuado. 
La Corte, por su parte, ha avanzado de manera significativa en la decisión pronta de las causas. Ella ha intentado diversas medidas de actuación que en conjunto le han permitido pronunciarse prontamente sobre los casos sometidos a su consideración. Por un lado, ha regularizado los plazos para todas las partes, aunque a veces se registra más flexibilidad hacia los Estados. Por otro lado, ha unificado el debate procesal en una única audiencia y decisión. El aspecto desfavorable de estas medidas es que la inflexibilidad de los plazos en ocasiones incide en las posibilidades reales de producir la prueba requerida.

(2). En cuanto a la producción de prueba ante la Corte, sigue constituyendo una limitante importante el aspecto económico que ella entraña. La inexistencia de fondos provenientes del propio Sistema para garantizar y facilitar la producción de prueba restringe el acceso en igualdad de condiciones y favorece a quienes cuentan con los recursos que demanda esta actividad procesal. La situación es aún más significativa si se tiene en cuenta que la Corte asume el conocimiento del caso con plena competencia para tener o no por demostrados los hechos presentados y las violaciones alegadas. Es decir, esta forma de operar permite, como lo indica la pregunta, la duplicación de funciones, dado que impone a las partes la necesidad de ampliar la prueba ya presentada y valorada por la Comisión. Esta es una carga de difícil soporte para quien no tiene acceso a los recursos necesarios.

(3). El rol de la Comisión y de las víctimas ante los procesos contenciosos de la Corte constituye un tema aún por decantar. Si bien la reforma a los Reglamentos introdujo mecanismos y herramientas formales que han procurado a las víctimas tener un papel más relevante en el litigio de los casos, lo cierto es que la ausencia de un reconocimiento más independiente de ellas puede impedir el efectivo acceso a la Corte. El tribunal ha establecido que el escrito de las víctimas o de sus representantes no es una demanda y que la exposición de los hechos está restringida a lo presentado por la Comisión en su propia demanda, a menos que se quiera explicar o ampliar un hecho. Esta es una posición que, en nuestra opinión, resulta limitante e injustificada. Si en todo caso la Corte puede evaluar y concluir la demostración de los hechos de manera diferente a como lo ha hecho la Comisión en su informe de fondo y en su demanda, ¿por qué en este actuar no puede considerar hechos adicionales que los representantes de las víctimas han alegado y que la Comisión no ha tomado en cuenta? Aceptar esta posibilidad no afectaría el equilibrio procesal, en la medida en que hablamos de hechos ya debatidos durante el trámite del caso ante la Comisión.

Sin perjuicio de ello, dada la dificultad y los obstáculos materiales para acceder a la Corte IDH, así como la falta de capacidad y capacitación en el litigio ante instancias internacionales, por ahora no debería modificarse el rol de parte de la CIDH. Es precisamente su participación, en estas condiciones, la que facilita la representación y litigio de los diferentes casos; en especial aquellos en que los peticionarios o las víctimas no cuentan con los recursos necesarios para hacerlo autónomamente.

\section{JUAN JOSÉ GÓMEZ CAMACHO}

3. Procedimiento

(1). Sin entrar en detalles acerca de la duración de los procedimientos y sin dejar de reconocer los avances que en este sentido se han logrado, los plazos actuales continúan siendo demasiado largos. En el caso de la Corte Interamericana (Corte IDH), por su propia naturaleza, existe cierto grado de razonabilidad en ello; pero en el caso de la Comisión se entiende en menor medida. Asimismo, ambos órganos todavía pueden explorar caminos para mejorar la situación.

El viejo debate sobre la certidumbre jurídica y la eficacia tiene que ver con este tema. Tanto víctimas como Estados deben contar con garantías procesales mínimas y una de ellas es la certidumbre 
sobre las etapas y tiempos del proceso. Debido a las zonas grises que frecuentemente se ven en el desarrollo de los asuntos, el círculo vicioso de las desconfianzas se fortalece.

Según creo, por lo menos en el caso de la Comisión Interamericana, se podrían restringir los plazos de diferentes etapas de manera tal que el procedimiento completo no exceda de 5 o 6 meses. En este sentido, son varias las opciones que deberían evaluarse: reducir los términos que las partes poseen para responder requerimientos de la Comisión Interamericana ${ }^{5}$; disminuir aún más la cantidad y los plazos de las prórrogas, las réplicas y las contrarréplicas, etcétera. Asimismo, sería útil explorar la posibilidad de crear procedimientos diferenciados para casos de especial gravedad y para aquellos que requieran un procedimiento más extenso.

(2). La duplicación de procedimientos es uno de los debates más complejos alrededor del SIDH. Según creo, aun cuando claramente es posible hacer algunos arreglos aquí y allá, el problema principal va a permanecer. El Sistema Interamericano no es de tipo bi instancial, en donde existe un órgano de primera instancia y un órgano revisor. El Sistema se integra por dos órganos diferentes: uno jurisdiccional que es parcialmente revisor de otro cuasijurisdiccional.

En este escenario, y atendiendo a las características de cada órgano, la Corte no puede renunciar a ninguna atribución jurisdiccional; ni respecto de la determinación de hechos ni, mucho menos, respecto de la determinación del derecho. Me parece que las grandes definiciones sobre este tema residen en el campo de la Comisión y guardan relación con el papel que esta quiera o deba tener en la promoción y protección de los derechos humanos. ¿Se quiere una Comisión más cercana a lo jurisdiccional? Si es así, ¿cuál debe ser su alcance y rol? ¿O, por el contrario, se trata de inclinarla más hacia la promoción, la asistencia y la cooperación? En cuyo caso, ¿cómo se administraría la parte jurisdiccional?

Lo que no se ve conveniente para enfrentar los serios retos del presente es una Comisión híbrida, con dilemas de identidad, que juega con sombreros diferentes y frecuentemente contradictorios.

(3). Dejando a un lado las enormes dificultades que implica cualquier negociación sobre este tema, me parece que el Sistema Interamericano debe tender al fortalecimiento de la representación independiente de las víctimas. Por lo que se refiere a la Comisión Interamericana, ésta debería modificar igualmente su papel, transformándose quizás en un "Amigo de la Corte", con un interés jurídico legítimo en las resoluciones de ella. Ahora, independientemente de cuál sea la mejor forma de replantear el tema, es indispensable resolver la enorme contradicción que significa el papel actual de la Comisión: primero como "árbitro" entre partes y luego como representante de una de ellas -la presunta víctima- en el litigio ante la Corte Interamericana.

Por más que la Comisión realice esfuerzos loables para mantenerse neutral durante todo el proceso, y sin cuestionar que efectivamente lo sea, en el esquema actual es imposible evitar la generación de percepciones tremendamente nocivas para el Sistema, los Estados y las víctimas.

\section{Procedimiento}

\section{CLAUDIO GROSSMAN, ROBERT K. GOLDMAN, CLAUDIA MARTIN Y DIEGO RODRÍGUEZ-PINZÓN}

(1). La continua crisis que enfrenta el Sistema Interamericano de Derechos Humanos hace casi imposible que los casos se tramiten en un plazo razonable, particularmente si los peticionarios esperan que todas las denuncias presentadas se resuelvan en forma individualizada por la Comisión y la Corte. Sin embargo, es central señalar que se deben proveer los recursos

5 Por ejemplo, el plazo para que los Estados respondan la primera solicitud de información de la Comisión (art. 30 № 3 del Reglamento de la $\mathrm{CIDH}$ ) podría reducirse a un mes. 
indicados al Sistema porque ninguna solución, en ausencia de estos recursos, es satisfactoria. Mientras la situación persista, se hace necesario buscar alternativas (paliativas) para enfrentarla. Algunos señalan que el debate sobre la razonabilidad de los plazos en el ámbito internacional debería evaluarse con una vara distinta a la que mide los procedimientos internos. Sin embargo, esa opinión no puede desconocer que cualquiera sea la vara utilizada, si los plazos no se cumplen el Sistema se deteriora. Alternativamente, podría alegarse que el establecimiento de un mecanismo de selección de casos contribuiría a que se acelere el trámite de peticiones individuales. Esto, por cuanto los órganos del Sistema resolverían menos denuncias y, en consecuencia, mejorarían su capacidad para emitir informes y sentencias en un plazo más breve.

(2). No existe duda de que la repetición de la prueba producida ante la Comisión y la Corte contribuye a la demora en la resolución de los casos del Sistema Interamericano de Derechos Humanos. Aunque la Corte incorporó en su Reglamento una disposición que le permitiría otorgar deferencia a la prueba rendida ante la Comisión (artículo 44.2), esta norma no parece haber sido aplicada en la práctica de manera consistente. La Corte ha estado dispuesta a otorgar deferencia a las decisiones de la Comisión únicamente con relación a la admisibilidad, y reservándose en casos de necesidad la facultad de reevaluar las conclusiones de dicho órgano. La política de la Corte de reproducir la prueba -por ejemplo, la testimonial- se ha llevado adelante aun frente a las reformas reglamentarias que la Comisión ha implementado a efectos de respetar el debido proceso y el principio de igualdad de armas en esta materia.

En principio, es incuestionable que la Corte debe aplicar su Reglamento e incorporar las pruebas rendidas ante la Comisión al expediente sin proceder a su reproducción, salvo que existan razones de peso que ameriten lo contrario. La Comisión, por su parte, debería hacer todo esfuerzo posible para ser rigurosa en la forma en que las recaba y produce en el marco de un caso individual. Si la Corte no estuviera de acuerdo con ciertos procedimientos de la Comisión, en vez de ignorar la existencia de su norma reglamentaria, debería indicar en sus decisiones las falencias identificadas en el caso concreto a fin de que se corrijan los aspectos cuestionables del procedimiento ante la Comisión.

(3). Desde la reforma de los Reglamentos de la Comisión y de la Corte se ha mejorado definitivamente el rol de la víctima en el procedimiento contencioso ante dicho tribunal. A su vez, la jurisprudencia de la Corte que permite a las víctimas alegar violaciones adicionales a las planteadas por la Comisión en su demanda, siempre que se trate de los mismos hechos, parecería otorgarles mayor independencia en la conducción del litigio y en la representación de sus intereses. En este contexto, el rol de la Comisión debería limitarse al de un "ministerio público" (que salvaguarda esencialmente el interés público), que representa los intereses del Sistema y no el de una parte que debe probar su caso. Así, la Comisión en el procedimiento ante la Corte debería permitir a las víctimas dirigir el litigio y restringirse a realizar aportes en aquellos aspectos que puedan afectar el alcance de las interpretaciones de los tratados aplicables o, a solicitud de la Corte, en otros aspectos procesales. La única excepción sería el caso de víctimas sin recursos, que requieran de una representación más activa por parte de la Comisión (por supuesto, siempre y cuando no se cree un fondo para solventar su propia representación). De este modo, la Comisión aprovecharía sus recursos en forma más eficiente y procesaría con mayor celeridad las peticiones que se presentan a su consideración.

\section{VIVIANA KRSTICEVIC}

3. Procedimiento

En la actualidad, las barreras más importantes para el acceso al Sistema Interamericano radican en la imposibilidad de la $\mathrm{CIDH}$ de dar respuesta a la mayoría de las peticiones y en el consiguiente proceso de selección informal de los casos que se analizan y deciden. 
A lo largo de los últimos diez años se han propuesto diversas soluciones a estos problemas, tales como el aumento del presupuesto, la ampliación del número de los miembros de los órganos, el establecimiento de una Comisión o Corte permanentes, la reforma de los procedimientos, el cambio de los roles de las partes en diversas etapas del proceso, la articulación de las Ilamadas estrategias "políticas" con las jurídicas, entre otras posibles.

En primer lugar, es necesario un diagnóstico que permita definir en mayor medida las características de los retrasos y de la informalidad del trámite de peticiones, con el objeto de verificar elementos que faciliten un mejor gerenciamiento del trabajo a futuro.

En segundo lugar, el procedimiento y las prácticas deberían modificarse para garantizar la centralidad de la víctima, la celeridad, la ausencia de ritualismos innecesarios, la previsibilidad y la transparencia. Es necesario que los casos sean resueltos teniendo en cuenta un orden cronológico, pero atendiendo a la vez situaciones excepcionales ${ }^{6}$.

También pueden pensarse otras medidas para mejorar la capacidad de decisión del Sistema y evitar su congestión: simplificar significativamente el formato de los informes de admisibilidad (siguiendo, por ejemplo, la práctica de la vieja Comisión Europea); unir el estudio de las admisibilidades con el fondo; respaldar activamente las soluciones amistosas; imponer plazos estrictos para el funcionamiento del propio Sistema; establecer salas para la determinación de admisibilidades; utilizar mecanismos de solución colectiva de conflictos (como decisiones per curiam o acumulación de casos, etcétera); modificar el formato de las demandas ante la Corte; replantear el papel de la $\mathrm{CIDH}$ en el proceso ante la $\mathrm{Corte}^{7}$; rever las modalidades de intervención de las víctimas en la totalidad del proceso ante el SIDH; sancionar la mala fe de algunos Estados en el litigio; evitar la duplicación de actos en el proceso ante la CIDH y ante la Corte ${ }^{8}$, etcétera.

Por otra parte, a los efectos de abordar los desafíos reseñados y como respuesta a la pregunta establecida por los editores/as de este Simposio, ¿el SIDH debería como primera, única o última medida pensar en la selección estratégica de casos y en la determinación de estándares? Si bien hay argumentos de buena fe para apoyar esta solución, considero que no es necesario y, más aún, puede ser riesgoso que el SIDH evolucionara en este sentido. Para fundamentar la negativa, es clave recordar la diferencia entre la estructura institucional de protección de derechos humanos a nivel internacional vis a vis aquella que en el plano doméstico ha permitido justificar soluciones similares para algunas cortes supremas o constitucionales. En el ámbito internacional no existen otras instancias de adjudicación de disputas y tampoco existen mecanismos claros para la incorporación de estándares y para el cumplimiento de sus sentencias en el plano local. Ello obstaculiza la posibilidad de asegurar que una decisión ejemplar actúe como factor de cambio. Más aún, el incumplimiento de las normas de los tratados de derechos humanos que interpreta el SIDH no está motivado, en la mayoría de los casos, por el desconocimiento de los estándares internacionales, sino más bien por los enfrentamientos deliberados con los compromisos inter-

6 Como las personas condenadas a pena de muerte, la determinación de los derechos de las personas privadas de libertad, la protección de los derechos de las personas en situación de riesgo de sufrir un daño inminente como el refoulment, etcétera.

7 En cuanto al papel de la $\mathrm{CIDH}$ en el litigio ante la Corte, creo que es posible y deseable modificar algunas de sus funciones. Este tema es uno de los grandes pendientes del Sistema. Por ejemplo, si bien la CIDH debe seguir cumpliendo un papel de garante de derechos ante la Corte, no debe duplicar o suplir innecesariamente el papel de la defensa de los derechos de las víctimas, como ocurre en ocasiones tanto en el debate del fondo como respecto a las reparaciones debidas, por ejemplo, interrogando a las víctimas sobre hechos o reparaciones alegadas por sus representantes.

8 A través, por ejemplo, de la adopción por parte del tribunal de un criterio general por el que se haga remisión a la determinación de la admisibilidad por parte de la Comisión, salvo en situaciones excepcionales. 
nacionales por parte de poderes de hecho o autónomos -como las fuerzas armadas, sectores de las fuerzas de seguridad, caudillos o líderes locales/regionales, etcétera-.

Adicionalmente, formalizar la posibilidad de elegir y evitar ciertos casos podría someter a la CIDH a presiones importantes por parte de los Estados. A su vez, el establecimiento de este tipo de procesos de selección estratégica exigiría la modificación del texto de la Convención Americana.

Por lo expuesto, es necesario recalcar la importancia del diagnóstico y la necesidad de tener la información adecuada antes de adoptar cualquier decisión con el objeto de aumentar la eficacia y capacidad del Sistema ${ }^{9}$.

\section{PEDRO NIKKEN}

3. Procedimiento

(1). La duración de los procedimientos ante la CIDH y la Corte presenta falencias importantes. Me limito a subrayar que el trámite es lento y su duración impredecible. Los plazos procesales no son siempre claros, especialmente ante la CIDH, y tampoco son respetados. Esto obedece, en primer lugar, a la limitación de recursos, incluida la dificultad de reunir materialmente a ambos órganos. También se observa que algunos casos avanzan más rápido, lo que puede explicarse por cierta jerarquía implícita, determinada por su urgencia o importancia contextuales; pero que en otras situaciones no tiene una explicación razonable.

(2). Las normas y actuaciones probatorias ante la CIDH y la Corte no se han coordinado suficientemente para permitir una más amplia aplicación del artículo 44.2 del Reglamento de la Corte. Teóricamente, sería deseable hacerlo, aunque en la práctica una ambiciosa meta para dotar de plenos efectos ante la Corte a la prueba producida ante la $\mathrm{CIDH}$ puede traducirse en mayores demoras. Primero, haría más compleja, costosa y lenta la fase probatoria ante la CIDH y, segundo, no podría impedir que la Corte tuviera que dar trámite a la pretensión de desvirtuar ante ella la prueba aceptada por la CIDH.

(3). Los derechos procesales que el Reglamento de la Corte ha reconocido a la víctima o sus representantes sugiere que la $\mathrm{CIDH}$ podría abandonar un tanto su función como parte demandante a lo largo del proceso y asumir más bien la condición de parte de buena fe, garante de la Convención, "a manera de ministerio público del Sistema Interamericano", como lo indicó la Corte en su más temprana jurisprudencia (Asunto de Viviana Gallardo y otras, párr. 22). Esto atendería al requerimiento de equilibrio procesal por parte de los Estados, que se quejan de tener que hacer frente a dos contrapartes, con idéntico poderío procesal, en los juicios ante la Corte. Esta es una idea que debe analizarse con cierta cautela, porque no todas las víctimas cuentan con un apoyo sólido para sus casos ante la Corte. Por otra parte, la CIDH conserva el monopolio de la iniciativa de la demanda y su reglamentación sólo le permite introducirla cuando ha concluido que el Estado ha violado la Convención, de manera que le es difícil asumir luego neutralidad ante la Corte. Una alternativa sería que la $\mathrm{CIDH}$ se limitara a interponer una demanda meramente instrumental, como acceso de las víctimas a la Corte, incluso cuando ha concluido que no se ha violado la Convención, supuesto en el que debería cooperar con la defensa del Estado ante el tribunal interamericano. El Sistema, empero, no parece maduro para estos cambios, que requieren de un cuidadoso estudio empírico sobre cómo se tramitan los casos ante la Corte bajo su actual concepto reglamentario.

9 Ello exige, entre otros, un análisis del dossier de casos actual de la CIDH que ronda en total las 1.500 peticiones, más un número indeterminado de denuncias no procesadas que podría poner las cifras sobre los 2.000 casos a resolver. 


\section{MÓNICA PINTO}

3. Procedimiento

(1). Debido, probablemente, a los elementos ya mencionados, la Comisión es la puerta de acceso al Sistema y, en ese hacer, recibe una enorme cantidad de presentaciones que debe analizar y clasificar.

El período de tiempo que media entre la efectiva recepción de una presentación y su análisis por la $\mathrm{CIDH}$, así como la decisión de trasladar la petición al Estado concernido para que informe, no está sujeto a parámetros fijos. De ordinario, es bastante prolongado y prácticamente no responde a ninguna regla. Esta situación conduce a una inevitable deslegitimación del Sistema. De hecho, por motivos relacionados con los tiempos, el mismo Sistema Europeo pensó en una renovación.

Por otra parte, el trámite de casos que se iniciaron según los procedimientos regulados en los antiguos Reglamentos conduce a resultados distintos de aquellos iniciados y regidos por los Reglamentos vigentes. De allí que existan casos que se han resuelto en tiempos breves y otros en los que debe afirmarse todo lo contrario ${ }^{10}$.

Los procedimientos ante la Corte IDH tienden a ser más cortos ${ }^{11}$ aunque, evidentemente, debe considerarse que el número de asuntos que ésta analiza es mucho más pequeño que el que tramita la Comisión. Además, los Reglamentos imponen plazos que se miden con mayor estrictez en la práctica cotidiana de la Corte que en la de la Comisión.

(2). La Corte IDH ha reconocido a la Comisión una función de investigación de los hechos. Desde un punto de vista sistémico y también a la luz de la mejor y más pronta reparación de la eventual violación de derechos humanos, no debería existir una duplicación de la producción de prueba. Sin embargo, ambos órganos del Sistema tratan de modo distinto el tema. Entre otras cosas, en la medida en que no se unifiquen los criterios y no se den los traslados de la prueba ante la Comisión con la misma rigurosidad que en el procedimiento judicial, no puede pensarse en la preclusión de las etapas. A tal fin, la informalidad actual de la Comisión requeriría de procedimientos estrictos de admisión, traslado, contestación y apreciación de la prueba.

Por otro lado, para que esto sea realizable, la Comisión no podría ser parte en el eventual litigio ante la Corte. Se afectaría la independencia y el equilibrio procesal si quedara en cabeza de una de las partes del conflicto la admisión y valoración de las pruebas ofrecidas por todas las involucradas. En este esquema, la Comisión sólo podría ejercer la función que le reserva el artículo 57 de la Convención, esto es, una suerte de Ministerio Público.

(3). El paulatino crecimiento del papel de las víctimas ante la Corte debería corresponderse con el de una Comisión que asuma el rol de Ministerio Público en defensa de los derechos humanos, más allá de las peculiaridades en los enfoques. Así, creo importante profundizar el camino hacia una legitimación activa plena de las personas ante la Corte y reevaluar el papel de la Comisión en dicho escenario. En este orden de ideas se inscribe, por ejemplo, lo que se plantea en el párrafo anterior respecto del trámite de la prueba.

\footnotetext{
10 Sólo para citar el último informe anual de la CIDH (año 2005) -disponible en www.cidh.org-, hay inadmisibilidades que se han declarado luego de cuatro años de trámite y admisibilidades que van de poco más de un año a un promedio muy superior.

11 Un promedio de 2 a 3 años y medio de tiempo.
} 
3. Procedimiento

\section{PAULO VANNUCHI}

(1). El creciente número de peticiones recibidas por la Comisión y la falta de criterios más precisos para su admisibilidad hacen que el tiempo de duración entre el conocimiento de la denuncia y la solución del caso (sea por vía de la solución amistosa, sea por la vía del cumplimiento de recomendaciones por el Estado, o incluso por la decisión de enviar la demanda a la Corte) resulte excesivamente largo. Debe prestarse atención al riesgo de que el proceso en aquella instancia repita las mismas fallas e imperfecciones de los sistemas judiciales nacionales, en lo que respecta a la celeridad. Se observa que no hay parámetros fijos para el tiempo promedio de tramitación de un caso en la Comisión y se verifica también que no existe una lógica objetiva en la selección de los casos que serán diligenciados por la propia $\mathrm{CIDH}$. Es condenable el uso de criterios políticos en la decisión discrecional de privilegiar casos de mayor "visibilidad", en detrimento de aquellos de menor envergadura.

Con relación al tiempo de duración de los procedimientos en la Corte, se observa que es más corto y más previsible que en la Comisión, lo que termina por otorgar una mayor credibilidad a aquella instancia.

(2). No hay que hablar de duplicación de funciones entre la Comisión y la Corte. Ambas deben actuar con independencia y respetando sus competencias. A pesar de que la Corte reproduce el proceso de producción de pruebas y de realización de audiencias, que también ocurre en la Comisión, el enfoque que se le da al tema es distinto. Cuando el caso se encuentra en análisis en la Corte, las partes del proceso pasan a ser, por un lado, el Estado y, por el otro, la Comisión y los peticionarios. Por consiguiente, tanto las pruebas producidas por el Estado como aquellas producidas por la Comisión y por los peticionarios serán igualmente evaluadas, sin distinción. La "igualdad de armas" se perjudicaría si una de la partes en el proceso ante la Corte, en este caso la Comisión, fuera en un momento preliminar responsable de la valorización de las pruebas presentadas por el Estado. Para que ello fuera posible, respetándose la independencia procesal, la Comisión no podría ser parte interesada en el proceso ante la Corte, debiendo ejercer un rol más cercano al de Ministerio Público.

(3). La Corte Interamericana de Derechos Humanos, tal como la europea, pasó a aceptar la participación de las víctimas durante todo el proceso, después de admitida la demanda, pudiendo éstas presentar sus peticiones, argumentos y pruebas de manera autónoma. A pesar de que se considera de extrema importancia que, en el futuro, las personas puedan tener acceso a la Corte directamente, hoy está perjudicada la defensa del Estado en lo que respecta a su tiempo de exposición oral. Actualmente, tanto la Comisión como las víctimas tienen igual oportunidad de presentación de pruebas y de expresión, mientras que al Estado no se le ha aumentado su tiempo para defensa, generándose un cierto desequilibrio procesal.

\section{Medidas cautelares}

\section{¿Cuál es su evaluación de los mecanismos de medidas cautelares/provisionales ante la Comisión y la Corte? ¿Qué problemas y desafíos presentan estos mecanismos?}

\section{GUSTAVO GALLÓN GIRALDO, LUZ MARINA MONZÓN CIFUENTES}

4. Medidas cautelares

Las medidas de protección del SIDH (medidas cautelares y medidas provisionales) constituyen un mecanismo de prevención y protección muy importante, que en realidad ha brindado respaldo y atención especial a situaciones de grave 
riesgo para las personas y las comunidades. Puede decirse que, incluso, han servido para salvar la vida de las personas.

A través de ellas, el SIDH actúa de manera oportuna sobre estas realidades y reclama de los Estados la adopción de decisiones que remedien la situación e impidan la consumación de la violación previsible en situaciones de riesgo. De esta manera, las medidas de protección tienen la gran potencialidad de incidir sobre la implementación de mecanismos internos y de políticas públicas que enfrenten las causas de eventuales afectaciones de derechos humanos.

En general, las situaciones puestas en conocimiento a través de las medidas de protección revelan circunstancias específicas que hacen parte de un contexto mayor, que implica la situación de una población más amplia. Por ello, la oportuna y efectiva intervención del SIDH mediante ellas podría incidir sobre esa situación general e, incluso, prevenir futuras violaciones de derechos humanos.

Los grandes problemas que presenta el SIDH frente a las medidas de protección radican en la ausencia de mecanismos eficaces, periódicos y efectivos que permitan su seguimiento y cumplimiento. Al mismo tiempo, tampoco se incide ante los Estados para reclamar la adopción de disposiciones específicas en el sentido propuesto.

Sin embargo, en nuestra opinión, la valoración sobre las medidas de protección tiene algunas singularidades diferenciadas frente a la Comisión y la Corte. La Comisión adolece de serios problemas de seguimiento y poca claridad sobre los procedimientos para su decreto y solicitud ante la Corte. La Comisión, una vez decretadas las medidas cautelares, limita su actuación a recibir y transmitir las comunicaciones de las partes, sin hacer ningún tipo de evaluación sustantiva. Esto incide en la eficacia cada vez menor que están teniendo estas herramientas. Algunas veces se logran hacer audiencias que permiten un seguimiento oral de las medidas tomadas y de aquellas descartadas. Sin embargo, la Comisión se muestra reticente a tomar decisiones, pese a observar la ineficacia práctica de las solicitudes de protección. Ello, incluso en casos donde algunas personas han sido asesinadas.

La Corte ha reclamado insistentemente de la Comisión una actuación más oportuna ante ella en caso de que las medidas cautelares se tornen ineficaces. Aún así, la Comisión no logra consolidar un criterio claro para determinar la solicitud de medidas provisionales a la Corte. Según lo indica la práctica, se requiere más que la ineficacia de las medidas para conseguir que la CIDH acuda ante ella.

En cuanto a las medidas provisionales, si bien la Corte otorga un trámite rápido y oportuno a las solicitudes de protección, la verdad es que el seguimiento está únicamente sometido a la presentación de informes de las partes y a la evaluación que se hace en determinados momentos. Los criterios que sigue la Corte para evaluar el cumplimiento de las medidas provisionales no se conocen. En ocasiones, si bien se solicitaron audiencias para discutir sobre los problemas de cumplimiento, éstas no se han logrado de manera periódica ni determinado según criterios claros.

En este contexto, la eficacia e importancia del mecanismo de protección ha presentado un debilitamiento que consideramos grave frente al papel preventivo de violaciones de derechos humanos que le compete al SIDH. En consecuencia, el gran reto que tiene el Sistema en este campo es implementar mecanismos de seguimiento que permitan hacer una evaluación adecuada y oportuna de las situaciones, así como también adoptar medidas que impongan consecuencias a los incumplimientos. 
4. Medidas cautelares

\section{JUAN JOSÉ GÓMEZ CAMACHO}

Nuevamente, en este tema hablo desde la experiencia estatal. Desde dicha perspectiva, encuentro muchas fallas que, en mi opinión, generan un sistema muy deficiente:

(a) Poca claridad en los criterios que se utilizan para determinar la procedencia de medidas cautelares/provisionales.

(b) Seguimiento y control limitados por parte de la Comisión, que provocan el mantenimiento y la vigencia indefinida de estas medidas.

(c) Incapacidad legal de la Comisión para asegurar su cumplimiento eficiente.

Debido a lo anterior, pero principalmente al hecho de que las medidas cautelares/provisionales son una herramienta indispensable de protección que debe garantizarse, entiendo que deberían ser siempre solicitadas por la Comisión a la Corte y, en su caso, emitidas por ésta. Ello no solamente resolvería los problemas mencionados sino que fortalecería sustancialmente el cumplimiento y eficacia de estas medidas.

4. Medidas cautelares

\section{CLAUDIO GROSSMAN, ROBERT K. GOLDMAN, CLAUDIA MARTIN Y DIEGO RODRÍGUEZ-PINZÓN}

Las medidas cautelares y provisionales se han constituido en una pieza crucial de las facultades y potestades de la Comisión y la Corte para descargar adecuadamente su mandato en materia de protección, en particular en aquellas situaciones donde existen violaciones graves, y a veces sistemáticas, de derechos humanos. Algunos Estados han reconocido a estas medidas en su ámbito nacional, el claro carácter vinculante que ellas tienen internacionalmente. Esto ha potenciado aún más la efectividad e importancia de ellas.

Desde luego, tanto la Comisión como la Corte acuden a las medidas interinas de protección sólo en casos realmente urgentes. En efecto, la efectividad de ellas depende de su utilización sopesada y cuidadosa. El cumplimiento de estas órdenes por parte de los Estados está supeditado a la legitimidad y credibilidad que tengan. Su uso inadecuado o laxo puede redundar en el menoscabo de su efectividad.

En este sentido tenemos que resaltar la reciente reforma del Reglamento de la Comisión Interamericana, en el cual parecen establecerse las bases para la tramitación de peticiones en forma más expedita frente a casos de gravedad y urgencia. De esta forma, la Comisión parece preservar todas las opciones en un caso de esta naturaleza, incluyendo la posibilidad de emitir medidas cautelares, solicitar medidas provisionales a la Corte, y/o tramitar el caso de forma más rápida.

No sobra indicar que sería inapropiada e inconveniente cualquier medida que exija que una petición deba ser abierta como "caso" para que pueda ser objeto de medidas cautelares de la Comisión. Esto iría a contravía de la naturaleza misma de las medidas cautelares y desvirtuaría la flexibilidad y rapidez con que la Comisión debe responder en casos de extrema gravedad y urgencia, que puedan ocasionar un daño irreparable. La adopción de medidas interinas dirigidas a evitar un posible daño, de ninguna manera implica prejuzgar en el mérito de una causa que pudiese abrirse en el futuro.

De otra parte, es importante que los miembros de la Comisión y la Corte sean cautos en sus apreciaciones públicas sobre la validez y eficacia jurídica de las medidas interinas de protección del Sistema. La percepción de obligatoriedad jurídica es, en gran medida, la base sobre la cual 
se sustenta el impacto que pueden tener dentro de los países. La integridad del Sistema descansa sobre estos pilares virtuales que son muy delicados y frágiles.

\section{Medidas cautelares}

\section{VIVIANA KRSTICEVIC}

Probablemente las medidas cautelares son el mecanismo que ha permitido tener mayor capacidad de tutela de derechos en el Sistema Interamericano. proteger una amplia gama de derechos, evolucionando sobre la práctica anterior de tutelar primordialmente la vida e integridad física. Adicionalmente, mediante estas medidas, se ha resguardado no sólo a individuos, sino también a grupos determinados, como en los casos de comunidades indígenas o de personas privadas de la libertad en centros de detención. Asimismo, se consolidó la práctica de no exigir el agotamiento de recursos internos ni la presentación de una petición para admitir la solicitud de medidas cautelares.

Sin embargo, miembros de los órganos y usuarios del Sistema (víctimas, Estados y ONG's, principalmente) han cuestionado algunas de las direcciones en las que ha avanzado el desarrollo de estas medidas. Los cuestionamientos se vinculan con la eficacia de las medidas cautelares; sus mecanismos, formas y plazos de monitoreo e implementación a nivel local; el papel de los órganos del SIDH en el aseguramiento de su ejecución; los instrumentos de verificación de información; la credibilidad de los peticionarios y el establecimiento de la verosimilitud de la amenaza urgente e irreversible invocada; la relación entre las medidas y el tratamiento de los casos individuales; el contenido que debe tener la medida para no reemplazar irrazonablemente a la decisión de fondo en el caso; el peso del contexto en las determinaciones; la importancia de mantener criterios consistentes en su concesión; la importancia de la denuncia de la situación de riesgo inminente a nivel local para la procedencia de las medidas, etcétera.

Varias de las preguntas e inquietudes todavía no tienen una respuesta. En este trabajo, dadas las limitaciones editoriales, quisiera únicamente Ilamar la atención acerca de la necesidad de avanzar en algunas de ellas, permitiendo asegurar la consolidación y el fortalecimiento de uno de los institutos más útiles de la protección interamericana.

\section{PEDRO NIKKEN}

4. Medidas cautelares

Las diversas modalidades de medidas de protección provisoria incluidas en el SIDH (cautelares de la CIDH, provisionales de la Corte, urgentes del

Presidente de la Corte, a las que en su conjunto aludiré como providencias cautelares) participan de un dilema implícito de estos mecanismos en todos los sistemas procesales. Así, las providencias cautelares representan una conciliación entre dos exigencias frecuentemente opuestas: la de justicia y la de celeridad; ellas implican una ponderación entre hacer las cosas pronto pero sin completa certeza y hacerlas con certeza pero tarde.

La Corte ha destacado reiteradamente una dimensión particular y adicional que tienen las providencias cautelares en el ámbito de los derechos humanos, donde además de su carácter esencialmente preventivo, protegen efectivamente derechos fundamentales y evitan daños irreparables a las personas. No se trata sólo (aunque también) de preservar los derechos en causa, sino de extender una tutela expedita para proteger a personas cuyos derechos estén frente a una amenaza de vulneración inminente e irreparable.

La lentitud del trámite ante el SIDH y la comprobada dificultad para que se cumplan las providencias restitutorias de las sentencias de la Corte, ponen de manifiesto la utilidad de las medidas 
cautelares en el Sistema, puesto que ellas apuntan hacia un remedio para esas falencias. Si se tutela un derecho amenazado y se previene que su violación se materialice o continúe, se protege a la víctima de manera eficaz y, al propio tiempo, se conjuran las deficiencias reparatorias del Sistema, reveladas por la práctica de defectuosa ejecución de sentencias.

Las providencias cautelares son, pues, útiles y necesarias. Es acertado que Comisión y Corte hayan interpretado con amplitud su ámbito de aplicación, sin restringirlo a supuestos extremos en los que peligra la vida o la integridad física de la víctima. La práctica del Sistema ha revelado que la restitutio in integrum, ordenada por la sentencia de fondo, es normalmente tardía e incompleta. En ese contexto, las herramientas procesales aptas para prevenir ese cuadro son, precisamente, las providencias cautelares. Esa amplitud de criterio de la $\mathrm{CIDH}$ y la Corte debería ratificarse y profundizarse.

\section{MÓNICA PINTO}

4. Medidas cautelares

El contexto juega un papel importante en el desarrollo de las medidas cautelares. De allí que el procedimiento fundamentalmente escrito conduce a diluir la autoridad del órgano que las dicta, en tanto que un procedimiento de debate oral y público compromete a los actores en mayor medida.

Sin perjuicio de lo anterior, el SIDH ha sabido desarrollar esta modalidad con reconocido éxito, más allá de los casos en los cuales la sola vocación política de algunos gobiernos no ha permitido evitar el gravamen irreparable.

Entiendo que las medidas previstas en el artículo 63 (2) de la Convención Americana son un buen ejemplo de complementariedad en la actuación de los órganos del Sistema. En este aspecto, la cooperación e interacción entre ambos no ha dado lugar a mayor debate y ha logrado una razonable protección de los derechos humanos de víctimas y testigos. Por ello, creo que el pedido debe ser rigurosamente estudiado o determinado por la Comisión y sólo llegar por la vía incidental a la Corte. A su vez, la Corte debe mantener en agenda el control del procedimiento de medidas provisionales, sin perjuicio de la prosecución del caso ante la $\mathrm{CIDH}$.

\section{PAULO VANNUCHI}

4. Medidas cautelares

Los mecanismos de medidas cautelares y provisionales han ejercido un importante papel en la eficacia de la protección de derechos en casos donde se presentan los elementos de extrema gravedad y urgencia. Se observa que, cuando cuenta con la cooperación de los Estados partes en el cumplimiento de las sentencias, dicho mecanismo se transforma en un verdadero aliado en la prevención de violaciones y en la solución de situaciones de riesgo inminente de sufrir violaciones.

Cabe resaltar que la Convención Americana estipula, en su artículo 63 (2), la posibilidad de que la Corte decrete medidas provisionales, pero nada menciona sobre la función de la Comisión para ordenar medidas cautelares. Dicha posibilidad está establecida sólo en el artículo 25 del Reglamento de la Comisión, lo cual puede producir ciertos cuestionamientos respecto de la legitimidad del referido mecanismo cuando sea determinado en esa instancia regional.

Tal vez sería más productivo para el Sistema si la Comisión se limitara al papel de evaluar rigurosamente las peticiones de medidas provisionales a la Corte, evitando así la pluralidad de mecanismos repetitivos, que termina debilitando sus efectos. Le corresponde a la Corte, a su vez, observar el tiempo de duración de las medidas de emergencia, sin dejar de lado la posibilidad de dar inicio 
a un procedimiento estándar en la Comisión. Cabe recordar que las medidas provisionales de duración prolongada ponen en duda la naturaleza del propio instituto, que debería condicionar su validez a las situaciones de extrema gravedad y urgencia.

\section{Eficacia del SIDH}

¿Qué tipo de medidas puede implementarse para mejorar el cumplimiento y ejecución local de las decisiones de los órganos del SIDH? ¿Qué actores locales e internacionales deben jugar un rol relevante en este sentido?

\section{Eficacia del SIDH}

\section{GUSTAVO GALLÓN GIRALDO, LUZ MARINA MONZÓN CIFUENTES}

Para mejorar el cumplimiento en la ejecución de las decisiones de los órganos del SIDH es necesario, en primer lugar, la definición de un mecanismo formal, específico y periódico de seguimiento, que permita detectar oportunamente las dificultades y las condiciones que no lo facilitan. Este conocimiento cercano y oportuno del estado de cumplimiento permitirá al SIDH proponer, diligenciar e implementar medidas adicionales hacia los Estados.

Ahora, si los problemas detectados tienen relación con la falta de voluntad política para el cumplimiento, como en gran parte ocurre, el SIDH deberá hacer uso de los órganos políticos de la OEA, en desarrollo de la garantía colectiva que les corresponde brindar. En razón de ello, no consideramos que sea conveniente la resolución adoptada por la Corte el 29 de junio de 2005, en la cual determinó su falta de competencia en el seguimiento. Deben conjugarse diversas medidas para lograr la superación de las dificultades detectadas en esta fase del proceso.

A su vez, otra de las herramientas que podría desarrollar el SIDH para obtener el cumplimiento de sus decisiones es facilitar de manera periódica y formal espacios de discusión y concertación entre los Estados, los peticionarios y los representantes de las víctimas, para escuchar sus posiciones y atender sus inquietudes. Podrían ser audiencias, seminarios o talleres.

En cualquier caso, el futuro rol del Sistema debe ser más protagónico que el actual. El SIDH ha desarrollado acciones que le han dado credibilidad y confianza a través de sus decisiones. No obstante, también debe asegurar su fortalecimiento mediante el efectivo cumplimiento de sus decisiones.

\section{Eficacia del SIDH}

\section{JUAN JOSÉ GÓMEZ CAMACHO}

En mi opinión, este tema se debe abordar desde dos puntos de vista: el legislativo y el práctico.

En el legislativo, por lo menos en el caso de México, se enfrenta un problema serio constituido por la falta de mecanismos legales que habiliten la implementación interna de los fallos o resoluciones. Al carecer de esta normatividad, el cumplimiento se ha hecho prácticamente imposible. Esto se debe resolver cuanto antes y es esencialmente una responsabilidad de los Estados.

En lo práctico, regreso nuevamente al tema de la cooperación y la asistencia. Los órganos deben entender mejor los serios obstáculos que frecuentemente enfrentan los Estados para cumplir sus obligaciones. No obstante, en el caso mexicano, la Comisión y el Gobierno encontraron mecanismos de cumplimiento altamente positivos y constructivos, en donde, mediante grupos de trabajo tripartitos, se lograron soluciones muy favorables para las víctimas. 
En esta misma línea, sería muy importante que por lo menos el Relator de la CIDH para México pudiera viajar al país a sostener este tipo de encuentros tripartitos. Esta es una posibilidad que debe fortalecerse.

\section{Eficacia del SIDH}

\section{CLAUDIO GROSSMAN, ROBERT K. GOLDMAN, CLAUDIA MARTIN Y DIEGO RODRÍGUEZ-PINZÓN}

Tal como indicamos en la primera parte de este documento, los Estados miembros deben tomar con seriedad su rol de garantes colectivos de la integridad del Sistema para garantizar su eficacia. Desde el año 2002, se han presentado varias iniciativas que buscan establecer un método de supervisión por parte de los Estados de la OEA del cumplimiento de las decisiones de la Comisión y la Corte. Sin embargo, hasta la fecha las únicas iniciativas implementadas fueron las de sus propios órganos, que crearon mecanismos de seguimiento de sus correspondientes decisiones. Aunque se ha podido incrementar la presión sobre los Estados respectivos, estas medidas no pueden reemplazar la acción decidida de los órganos políticos de la OEA.

Otro aspecto central para mejorar la eficacia del Sistema es el de la armonización de los ordenamientos normativos internos con los estándares y mecanismos interamericanos. La mayoría de los Estados no ha tomado las medidas necesarias que permitan cumplir completa y adecuadamente con las decisiones y sentencias de la Comisión y la Corte. Algunos han adoptado los componentes pecuniarios de las decisiones a través de medidas administrativas o de otro carácter, pero la gran mayoría carece de mecanismos para, por ejemplo, revisar decisiones judiciales que han formalizado la impunidad en ciertos casos, amparándose en la cosa juzgada o la prescripción, entre otros. Para lograr un cambio será necesaria la intervención concertada de organizaciones de la sociedad civil, abogados, jueces, funcionarios públicos, profesores, y muchos otros actores con incidencia en políticas públicas.

Por otro lado, como hemos mencionado, los órganos del Sistema, y en particular la Comisión, han tenido ya una larga relación simbiótica con las organizaciones de derechos humanos que representan víctimas en los países de las Américas. Esta ha sido la audiencia natural de estos órganos para comunicarse formal e informalmente. Sin embargo, tanto la Comisión como la Corte deben tener en cuenta que por medio de sus informes, decisiones y sentencias también están entablando un diálogo con los operadores estatales relevantes para la protección de derechos humanos. Por esta razón, es esencial preservar el rigor jurídico del análisis que, además de proyectar la dimensión vinculante del Sistema, le permitirá articularse de mejor manera con las estructuras constitucionales nacionales. A esto se suma la adopción de medidas más sencillas que pueden facilitar dicha comunicación, como la producción, en lo posible, de decisiones menos voluminosas y más accesibles para jueces, funcionarios públicos, docentes, editores, estudiantes, y otros actores interesados en contribuir al Sistema.

Finalmente, es muy importante que los gobiernos no perciban al Sistema Interamericano como un obstáculo para cumplir con los objetivos que les han sido señalados por sus electores, sino como una herramienta más que pueden utilizar para apoyar y empoderar esos esfuerzos.

\section{VIVIANA KRSTICEVIC}

5. Eficacia del SIDH

El debate sobre la eficacia del Sistema Interamericano comprende pero, a la vez, excede la implementación de las decisiones de sus órganos. Un debate integral sobre esta materia debe incluir aspectos legales, políticos e institucionales, tales como: la autonomía de los órganos; la relación entre las normas e interpretaciones del 
Sistema y la legislación, jurisprudencia, práctica y política a nivel nacional; el impacto de los procesos de selección de miembros (composición) de la $\mathrm{CIDH}$ y de la Corte en sus capacidades de actuar; la relevancia de la universalidad del Sistema en su legitimidad y autoridad, entre muchos otros.

No obstante, no cabe duda alguna que la implementación de las decisiones de los órganos del Sistema Interamericano es un asunto de capital importancia en la determinación de su eficacia. Ahora bien, la experiencia ha mostrado que la ejecución de sus decisiones depende en buena medida de la estructura institucional y legal existente en los países. Sin embargo, también influyen -en algunos casos de manera determinante- factores como la capacidad de incidencia de las Organizaciones No Gubernamentales, la buena voluntad de funcionarios/as de diversos poderes del Estado, el papel de la prensa, el comportamiento de muchos actores políticos en la región, entre otros.

Así, a fin de allanar la ejecución de las medidas internacionales, el Poder Ejecutivo en gran parte de los países de América tiene el desafío de generar políticas de cooperación con el Sistema Interamericano, que respondan adecuadamente a las obligaciones internacionales asumidas. Por su parte, en esta materia, las legislaturas tienen un importante camino por delante en el desarrollo de normas globales y en la reforma de la legislación existente.

A su vez, el Poder Judicial tiene espacios importantes de trabajo en la definición de políticas -expresadas en la elaboración de directrices, acordadas y jurisprudencia- que permitan resolver algunos dilemas que se presentan al ejecutar las decisiones del Sistema -aun cuando no haya legislación específica sobre el tema-. Por ejemplo, en lo relativo a la definición de competencias para la implementación de las decisiones del SIDH; en la determinación de los procedimientos aplicables; en la precisión del alcance de institutos jurídicos fundamentales como la prescripción y el non bis in idem frente a la obligación de investigar y castigar graves violaciones a los derechos humanos; en el establecimiento de unidades especiales de investigación, entre otros campos posibles.

Asimismo, la propia OEA podría asumir un mayor respaldo a sus órganos de derechos humanos, a través de un debate más amplio sobre el cumplimiento de sentencias, que apoye y no erosione los procesos de vigilancia del cumplimiento de las obligaciones contraídas.

Finalmente, otro actor clave frente a estas discusiones es la comunidad jurídica a nivel nacional e internacional. Ella puede facilitar discusiones doctrinarias con participación de expertos/as, académicos/as, miembros de la administración de justicia, entre otros. Así, existe un amplio margen de discusión sobre temas jurídicos de enorme relevancia, que necesariamente deben incluir a estas voces.

5. Eficacia del SIDH

\section{PEDRO NIKKEN}

La Convención consagra, en mi parecer, el derecho de petición ante los órganos del Sistema. Este derecho se deduce implícitamente del artículo 44 de la misma Convención y de las disposiciones pertinentes del Estatuto de la CIDH y de los Reglamentos de la misma CIDH y de la Corte. Para que este derecho sea efectivamente realizable (efecto útil), las decisiones de los órganos del Sistema deben quedar cubiertas por las obligaciones estipuladas en el artículo 2 de la Convención. Esta última disposición, tal como ha sido rectamente interpretada por la Corte (supra, 2), representa una pieza de significativa importancia para la garantía de los derechos humanos reconocidos por la misma Convención, cuya utilidad no ha sido aún aprovechada en toda su potencialidad. 
Dicha garantía implica cierto número de obligaciones a cargo de los Estados parte. Algunas de esas obligaciones son de contenido positivo, en el sentido de que implican un hacer por parte de los órganos del poder público, mientras que otras son negativas, en cuanto comportan prohibiciones que limitan la esfera de actuación legítima de dichos órganos. Quedan así comprendidas: (1) la obligación de adoptar sin dilación disposiciones de Derecho interno necesarias para hacer efectivos los derechos humanos reconocidos en la Convención; (2) la obligación de suprimir toda norma o práctica incompatible con los deberes que la Convención impone a los Estados parte; (3) la prohibición de dictar normas u otros actos, así como la de establecer prácticas violatorias de la Convención; (4) la prohibición de aplicar o dar cumplimiento a leyes u otras normas violatorias de la Convención, y (5) la obligación de adoptar las medidas legislativas o de otro carácter necesarias para hacer efectivas las decisiones o recomendaciones de la Comisión y las sentencias y demás providencias de la Corte.

Algunos Estados han adoptado leyes (de diferente alcance) destinadas a la ejecución en la jurisdicción nacional de decisiones de órganos internacionales a cuya jurisdicción están sometidos (Colombia, ley № 288, de 5 de julio de 1996; Perú, ley Nº 27775, de 5 de julio de 2002; Costa Rica, ley aprobatoria del Convenio de Sede con la Corte). La generalización de estos esfuerzos crearía un cuerpo de disposiciones legislativas y de otro carácter para dotar de fuerza ejecutoria en la jurisdicción nacional a las decisiones de los órganos del SIDH.

Naturalmente, hay ciertas decisiones para cuya ejecución no bastan esos mecanismos, pues requieren de actos institucionales que dependen de la voluntad política del Estado, como ocurre con la mayor parte de las providencias relativas a la restitución, la no repetición (reformas legislativas o administrativas, por ejemplo), y la satisfacción (actos de desagravio público, entre otros).

Esto nos coloca de nuevo frente a una realidad insalvable: la voluntad y la seriedad del compromiso asumido por los Estados con respecto al SIDH son, y no pueden dejar de ser, las columnas de la ejecución local de las decisiones de Comisión y Corte. Su efectividad, en última instancia, depende de la determinación con la que los Estados que han contribuido a crear el SIDH estén dispuestos a honrar los compromisos que han contraído. La sociedad civil tiene, en este campo, funciones de vigilancia y de exigencia que deben ser asumidas con el mayor celo. También podrían arbitrarse mecanismos efectivos (y no de puro trámite como ocurre en el presente), para que los órganos políticos de la OEA (CP y AG), evaluaran con seriedad el cumplimiento de las obligaciones de sus miembros con respecto a las decisiones de la Comisión y de la Corte Interamericanas de Derechos Humanos.

\section{MÓNICA PINTO}

5. Eficacia del SIDH

En términos generales, un sistema puede ser calificado de eficaz cuando la brecha entre las normas particulares -informes de la $\mathrm{CIDH}$, sentencias de la Corte IDH - y su ejecutoridad no asume la característica de un ángulo agudo con tendencia a recto o llano. Cuando las normas particulares están demasiado lejos de las efectividades conducentes, su importancia se diluye.

Una interpretación rigurosa de los alcances del Sistema, en mejores tiempos y con mayor fundamento jurídico; mecanismos que permitan considerar la opinión de los órganos del SIDH como causal de revisión o nulidad de sentencias en el ámbito interno; una nueva lectura de la noción de "cosa juzgada" que habilite la pronta ejecutoriedad de las decisiones de la Corte; entre otros aspectos, deberían conducir a la eficacia. Ello podría corresponderse con un más marcado interés de la comunidad interamericana por el grado de cumplimiento de las sentencias de la Corte, de manera tal de construir la voluntad política necesaria para garantizar su ejecución. 
5. Eficacia del SIDH

\section{PAULO VANNUCHI}

La promoción y difusión del SIDH entre los diferentes organismos de los ámbitos federal, estatal y municipal, incluidos los poderes ejecutivo, legislativo y judicial, son cruciales para el mejoramiento del cumplimiento y ejecución local de las decisiones tomadas por los organismos del Sistema.

En el caso de Brasil, por ejemplo, que posee un sistema federativo de organización política, la existencia de la soberanía de la Unión y de la autonomía de las entidades federadas (Estados, Municipios y Distrito Federal) implica un importante obstáculo en el cumplimiento y ejecución de las decisiones de los organismos del SIDH, dado que los entes federados no participan ni se involucran en el compromiso del Estado brasileño frente a las obligaciones internacionales, que es representado por el Poder Ejecutivo Federal.

El mayor desafío interno es sensibilizar a los demás entes de la federación con relación a la idea de que los compromisos asumidos internacionalmente son de responsabilidad de todos, no sólo del Gobierno Federal. La mayor dificultad está en la difusión de un concepto según el cual las responsabilidades se comparten y todos los actores ejercen un rol relevante y fundamental frente a ellas.

Deberá incentivarse también una cooperación más estrecha entre los poderes, ya que ésta permitirá elaborar e implementar acciones integradas en el sentido de cumplir con las resoluciones del Sistema. Otro mecanismo imprescindible para el cumplimiento y ejecución de las decisiones es la elaboración de una legislación específica que regule y adopte procedimientos internos. Un mecanismo de esa naturaleza evitará que las prácticas públicas caigan en el olvido en función de los cambios de coyuntura política, permitiendo la consolidación de verdaderas políticas de Estado en aras del fortalecimiento del Sistema Interamericano de Derechos Humanos. 